\title{
Low frequency induction thermography for the characterization of hidden cracks in ferromagnetic steel components
}

\author{
by G. Walle, U. Netzelmann, C. Stumm and B. Valeske
}

Fraunhofer Institute for Nondestructive Testing IZFP, Campus E3 1, 66123 Saarbrücken, Germany, udo.netzelmann@izfp.fraunhofer.de

\begin{abstract}
Induction thermography has been extended to the low frequency range of 300 to $2600 \mathrm{~Hz}$. The electromagnetic skin depth is thereby increased in a way that in ferromagnetic steel hidden defects with 1.25 mm coverage could be detected by interaction of the induction currents with the crack. Numerical simulations of the internal current and temperature distributions were performed. Experimentally, artificial and natural cracks were studied. The influence of the electromagnetic excitation frequency was investigated. In plate-like geometries with hidden cracks starting at the backside, an inversion of the defect contrast with frequency was observed and explained by simulation.
\end{abstract}

\section{Introduction}

Induction thermography is an active thermal testing technique for the characterization of ferromagnetic as well as austenitic steel components for surface cracks, pores and other inhomogeneities in the surface near region [1-7]. Due to its contactless and fast operation this nondestructive thermographic testing technique shows a high potential for the fully automated In-line characterization of steel components in various industrial sectors, e.g. automotive industry or steel industry. Especially in ferromagnetic steel components it was not possible up to now to detect hidden crack-like defects. New developments based on low frequency excitation now allow the detection of such cracks.

\section{Low frequency induction thermography, physical principles, simulations and experiments}

\subsection{Characterization of hidden cracks without contact to the back surface}

Induction thermography is primarily based on the interaction of eddy currents with cracks for the detection of these defects. The eddy currents excited by a high frequency electromagnetic field are disturbed by surface cracks in their propagation in the material. This is leading to changes in the current density in the neighborhood of the defects and hence characteristic temperature fields occur at the specimen surface indicating the defects. Cracks hidden below the surface in ferromagnetic components do not interact with the eddy currents which are concentrated in a thin surface layer of the material at high frequencies (skin effect). For example, at frequencies of a few 100 to $300 \mathrm{kHz}$, the skin depth in ferromagnetic steel is only about $50 \mu \mathrm{m}$. By using low frequency excitation in the range of $1 \mathrm{kHz}$ it is possible to increase the skin depth and generate eddy currents with a skin depth in the region of 1 millimeter or more, where they can still interact with hidden defects electromagnetically (figure 1, left). So the current density is changed in the vicinity of the defect, leading to spatially changed eddy current losses. These changes in eddy current losses produce transient heat flows generating characteristic temperature fields at specimen surface over the defect (figure 1, right).

Induction thermography uses two physical phenomena for the characterization of crack like defects. These are first the electromagnetic induction law, which describes the eddy current excitation in electrically conductive materials, and, second, transient heat propagation. Both phenomena are coupled in a sense that by the electromagnetic excitation eddy current losses are produced and hence heat sources causing a transient heat propagation. On basis of these coupled physical phenomena two dimensional model calculations were performed using COMSOL Multiphysics in order to calculate the temperature fields at the specimen surface over a defect. A specimen with a rectangular cross-section (xy-plane) extending to infinity in the z-direction was assumed containing a defect with a rectangular cross-section extending to infinity in z-direction (see figure 1, left). Furthermore, the exciting magnetic fields are oriented in z-direction. First, it was assumed that the defect has a depth position of $0.5 \mathrm{~mm}$ below the surface and a depth extension of $1.0 \mathrm{~mm}$. In figure 1, left, the calculated current density in the neighborhood of the defect is shown in a color coded image for an excitation frequency of $300 \mathrm{~Hz}$. Red and yellow colors indicate a high eddy current density, blue colors represent a lower current density. Furthermore, the red arrows indicate the magnitude and the direction of the eddy currents in the region of the defect. As can be seen from this image, the eddy currents, which have a skin depth of about $0.9 \mathrm{~mm}$ for this frequency, are disturbed by the defect in their propagation. The currents lines are bent away partly over the defect causing a concentration of the eddy currents and hence an increased eddy current density. Therefore in that region above the defect increased eddy current losses occur causing heat flows to the surface which there produce a characteristic temperature field (defect signal) revealing the defect below the surface. The heat propagation was calculated simultaneously in the simulation and the result is presented in figure 1, right. In this image the temperature contrast (temperature signal) produced by the defect can be recognized (the red line marks the surface of the specimen). 

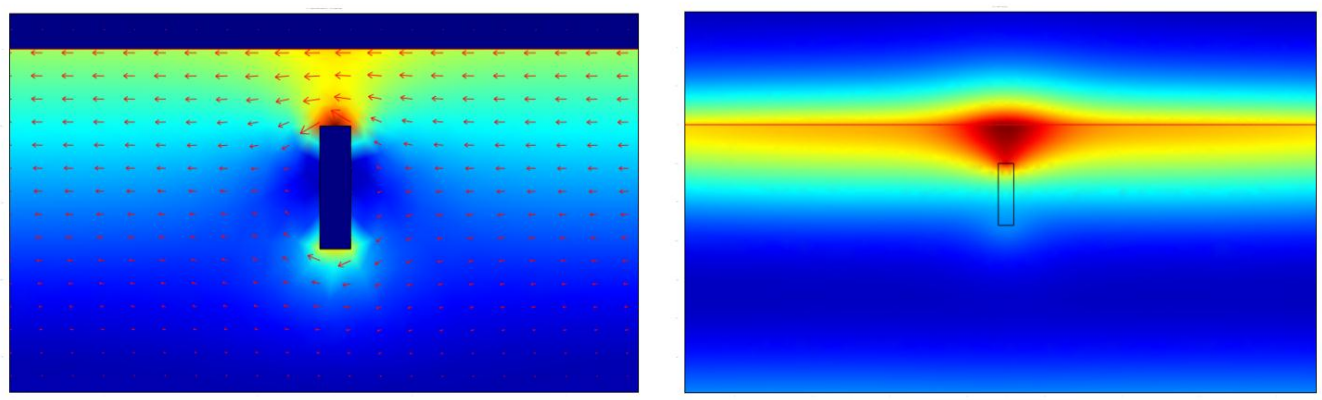

Fig. 1. Left: Model calculation of the eddy current density in the vicinity of a hidden crack with a depth position of $0.5 \mathrm{~mm}$ below the surface at an induction frequency of $300 \mathrm{~Hz}$. Right: Model calculation of the resulting temperature distribution in the vicinity of a hidden crack due to the eddy current losses. Both images show a cross-section of the sample

In order to find an optimum frequency for the defect detection (with maximum absolute contrast) of hidden cracks, calculations for various frequencies and depth positions were performed. The results are presented in figure 2. For a depth position of $0.25 \mathrm{~mm}$ one finds an optimum frequency of about $2000 \mathrm{~Hz}$ (skin depth about $0.35 \mathrm{~mm}$ ). If the depth position is $0.5 \mathrm{~mm}$ the optimal frequency is about $1000 \mathrm{~Hz}$ (skin depth about $0.5 \mathrm{~mm}$ ). The model calculations show that crack like defects up to a depth position of about $1 \mathrm{~mm}$ can be detected if the depth extension of the crack is 1 $\mathrm{mm}$ or more and the frequency is in the range of $300 \mathrm{~Hz}$ (skin depth about $0.9 \mathrm{~mm}$ ).

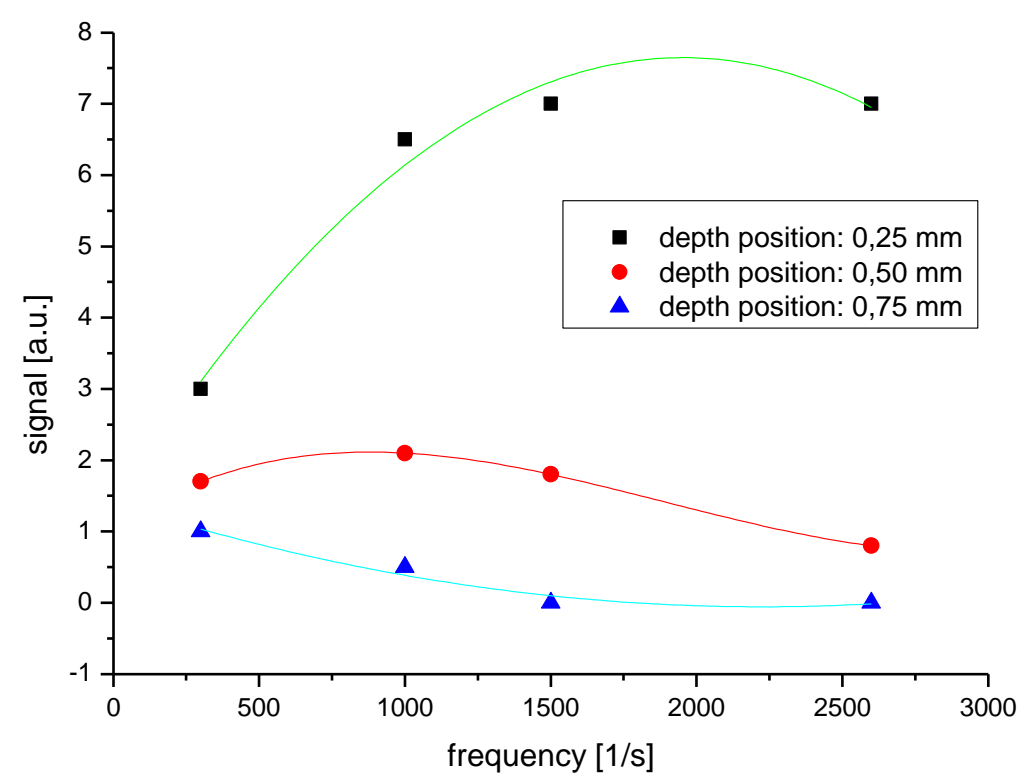

Fig. 2. Model calculations of the defect signal in dependence of induction frequency for various defect depth positions

For the case of a natural imbedded crack in a ferromagnetic steel sample an experimental result can be presented. An induction generator that was able to deliver an excitation frequency of $1500 \mathrm{~Hz}$ was employed. The component was not blackened. The results presented in figure 3 were obtained. They show a clear crack indication in this component. The same specimen was also examined using high-frequency induction excitation at $100 \mathrm{kHz}$. The latter result is shown in figure 4 , left. In this case, the defect produced only a very weak signal. A subsequent metallographic examination showed that in this specimen a crack occurred (see figure 4, right). This crack had no contact to the surface but started about $140 \mu \mathrm{m}$ below the surface and extended down to a depth of about $3 \mathrm{~mm}$. Therefore the eddy currents at a frequency of $100 \mathrm{kHz}$ (skin depth: about $50 \mu \mathrm{m}$ ) could not intensively interact with the crack. In contrast, at a frequency of $1500 \mathrm{~Hz}$ (skin depth: about $0.4 \mathrm{~mm}$ ) there was a strong disturbance of the eddy currents by the crack causing the clear temperature signal. 

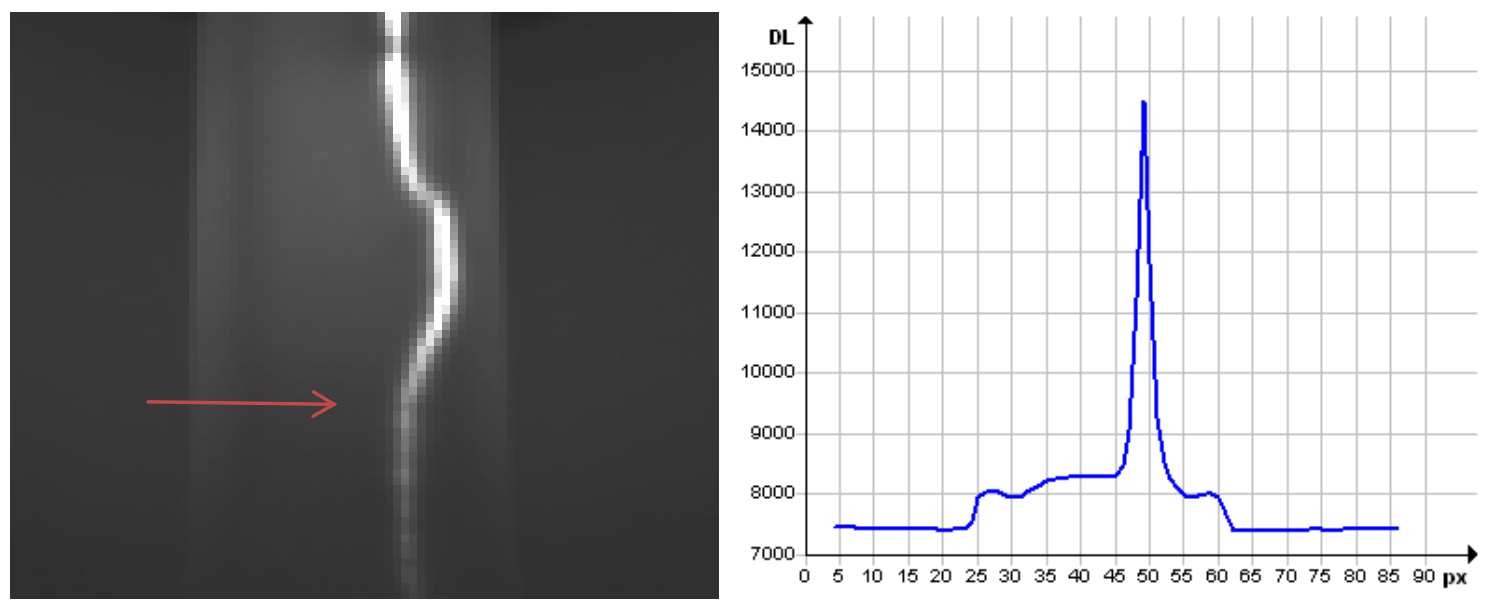

Fig. 3. Left: Thermographic image of a ferromagnetic steel component with a natural hidden crack excited at $1500 \mathrm{~Hz}$. Right: signal profile (in digital levels DL) along the arrow in the left figure.
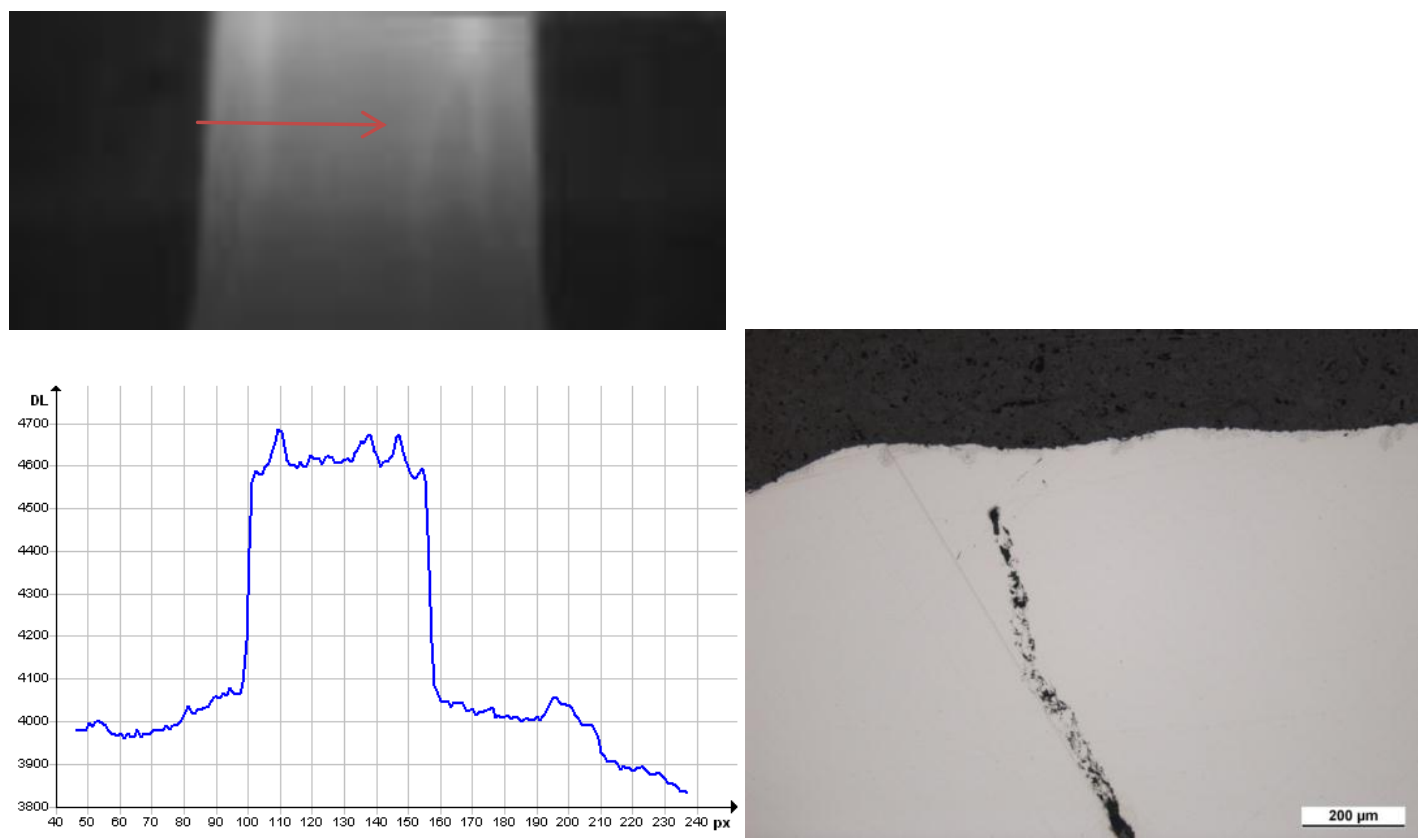

Fig. 4. Left top: Thermographic image of the ferromagnetic steel component from figure 3 obtained at an induction frequency of $100 \mathrm{kHz}$. Left bottom: signal curve (in digital levels) along the arrow in the thermographic image. Right: Metallographic cross-section along the arrow. A hidden crack is present at a depth position of about $140 \mu \mathrm{m}$.

\subsection{Characterization of hidden cracks open to the back surface}

In order to verify the model calculations, measurements on a plate with artificial defects (saw-cuts from the back side of the plate surface) were performed using low-frequency induction. For this purpose saw cuts with a length of $10 \mathrm{~mm}$ with various depths were machined into a slab with a thickness of $3 \mathrm{~mm}$. The material was ferromagnetic mild steel. In this way hidden cracks were produced placed in different depth positions below the front surface of the plate. The plate was excited with a frequency of $300 \mathrm{~Hz}$ and the resulting temperature signals of the hidden defects were measured with an infrared camera and evaluated using the ThermoLab thermography software system of the IZFP. The measured defect signal of the crack with a depth position of $1.25 \mathrm{~mm}$ below the front surface is shown in figure 5 . The plate was blackened on the surface, in order to improve thermal emission. In the thermographic image of figure 5, left, a clear negative temperature contrast can be recognized at the specimen surface above the defect. In figure 5 , right, 
representing the defect signal profile at the specimen surface along the arrow in figure 5 , left, the negative defect signal shows a good signal to noise ratio for this defect. Remembering the positive contrast from hidden cracks presented before by the model calculations and in the measurement (figures 1 and 3), the result of a negative temperature contrast for the hidden, artificial crack in the steel plate is surprising.

In order to investigate the origin of the observed behavior, 2D model calculations using the geometry of plates with defects in various depths from back side were performed. In figure 6, left, the result of a model calculation for the current density of the eddy currents at a frequency of $300 \mathrm{~Hz}$ with a defect in a depth position of $1.25 \mathrm{~mm}$ below the surface is presented. As can be seen from the current lines (arrows), the eddy currents in this case cannot propagate along the backward surface but are disturbed by the surface crack on the back side and flow along the crack. As a consequence of this and due to the relatively high skin depth of the eddy currents of about $0.9 \mathrm{~mm}$ two separated eddy current loops at the left side and the right side of the crack are generated in the plate. The result is a lower eddy current density above the defect in the area between the crack tip and the surface, as it can be recognized in figure 6 , left. The eddy current losses above the defect are smaller in comparison to the surroundings of the defect. Therefore a negative temperature contrast occurs above the defect. The corresponding model calculation of the temperature field at the specimen surface is shown in figure 6 , right. In figure 7 , the calculated temperature profile over the hidden defect along a line at the top specimen surface is presented, showing the negative defect signal.
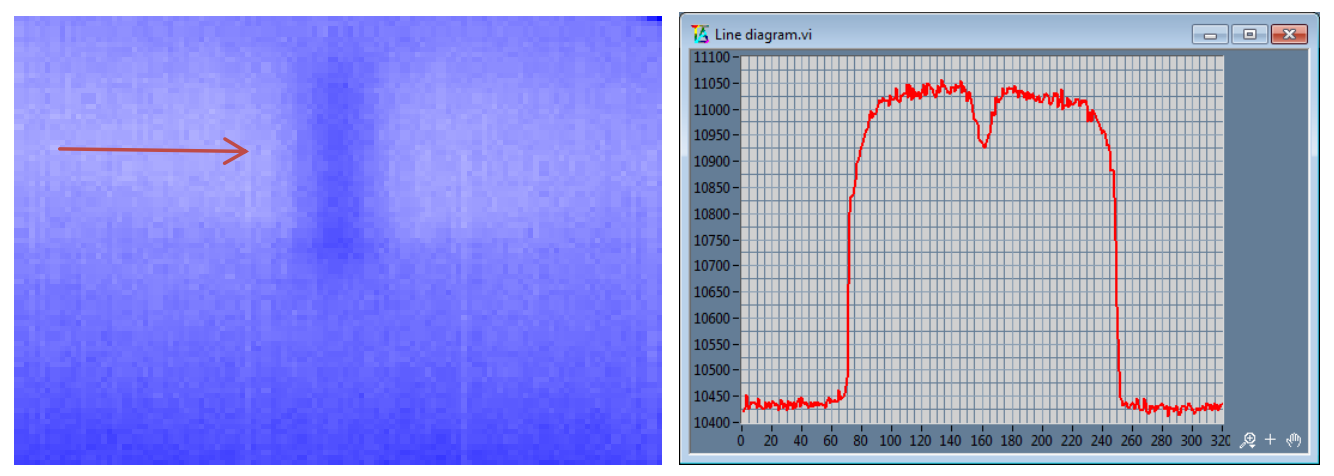

Fig. 5. Left: Thermographic image of a mild steel plate at a frequency of $300 \mathrm{~Hz}$. A defect indication from an artificial hidden defect at a depth position of $1.25 \mathrm{~mm}$ with a length of $10 \mathrm{~mm}$ is visible (image size about $40 \mathrm{~mm} \times 30$ $\mathrm{mm}$ ). Right: signal profile (in digital levels) along the arrow in figure 5, left.
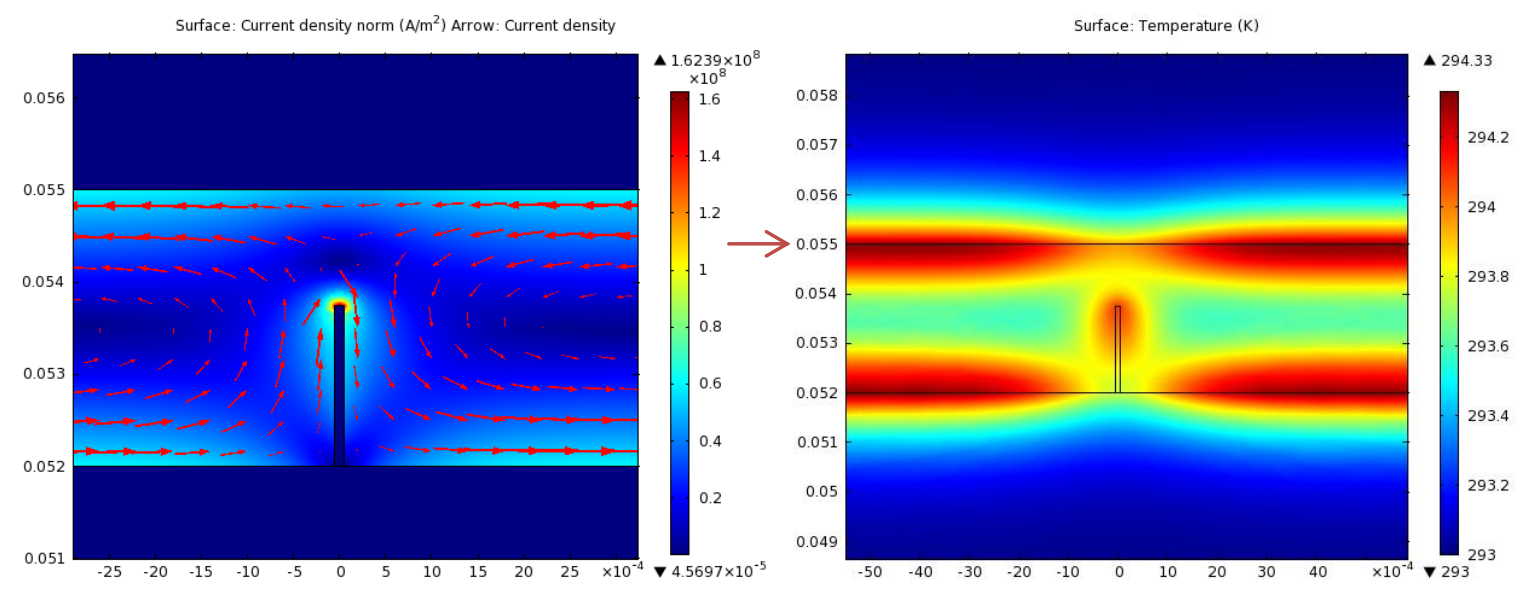

Fig. 6. Left: Simulation of the induction current density around the crack from the back side with a depth position of the crack of $1.25 \mathrm{~mm}$ and a frequency of $300 \mathrm{~Hz}$. Right: Simulation of the temperature distribution around the crack. Both images show a cross-section of the sample 


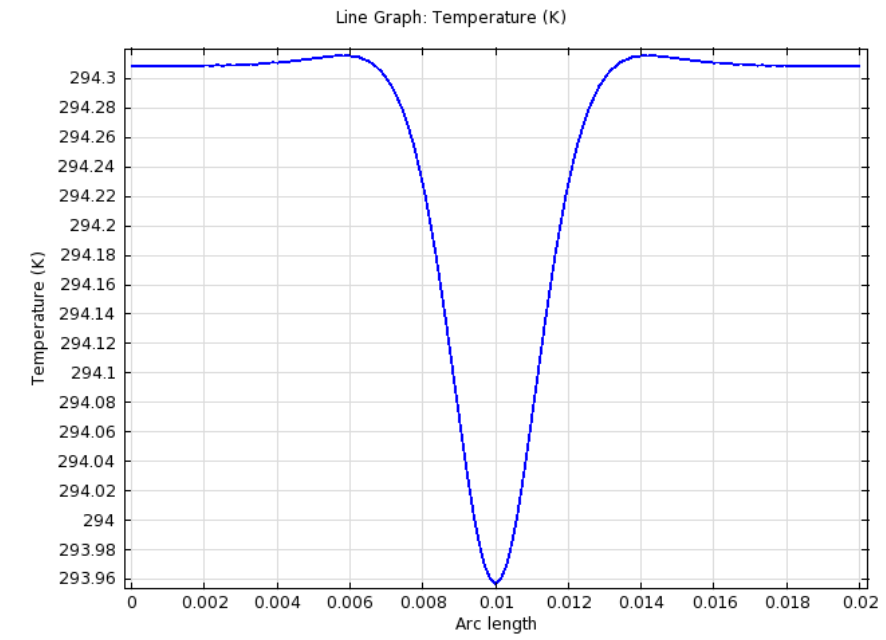

Fig. 7. Calculated surface temperature profile over the hidden defect (along the arrow in figure 6, right) showing the negative defect signal

For the same defect, the behavior of the defect signal as a function of the induction frequency was examined. At a frequency of $2600 \mathrm{~Hz}$ (skin depth about $0.3 \mathrm{~mm}$ ) a defect signal was detected which was no more negative but now a clearly positive signal was observed (figure 8 , compare to figure 5).
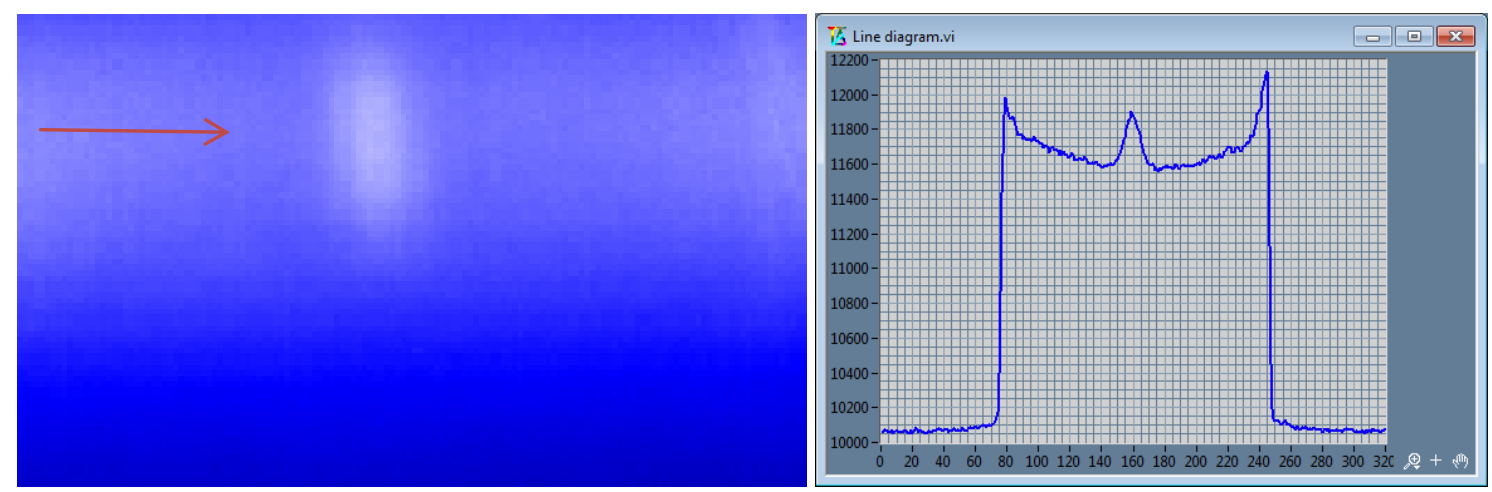

Fig. 8. Left: Thermographic image of a mild steel plate at a frequency of $2600 \mathrm{~Hz}$. A defect indication from an artificial hidden defect at a depth position of $1.25 \mathrm{~mm}$ with a length of $10 \mathrm{~mm}$ is visible (image size about $40 \mathrm{~mm} \times 30$ $\mathrm{mm}$ ). Right: signal profile (in digital levels) along the arrow in figure 8, left.

For this frequency the corresponding model calculation shows another behavior of the eddy current lines (figure 9 , left). In this case the eddy currents on the back side of the plate are able to pass the tip of the defect and form only one current loop. Therefore the eddy currents at the front side are not disturbed by the defect. Nevertheless, in this case a clear positive defect signal above the defect is obtained (see figure 10) due to the high current density at the crack tip causing intense heat sources and a heat flow to the surface. 

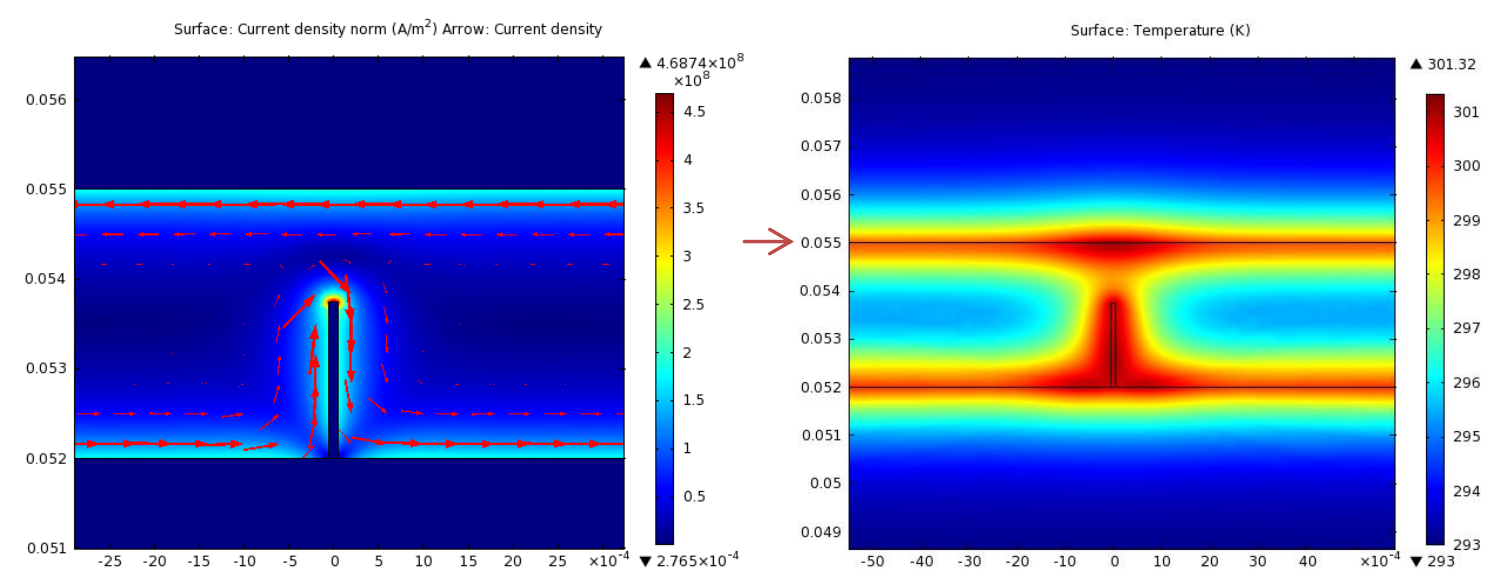

Fig. 9. Left: Simulation of the induction current density around the crack from the back side with a depth position of the crack of $1.25 \mathrm{~mm}$ and a frequency of $2600 \mathrm{~Hz}$. Right: Simulation of the temperature distribution around the crack.

Both images show a cross-section of the sample

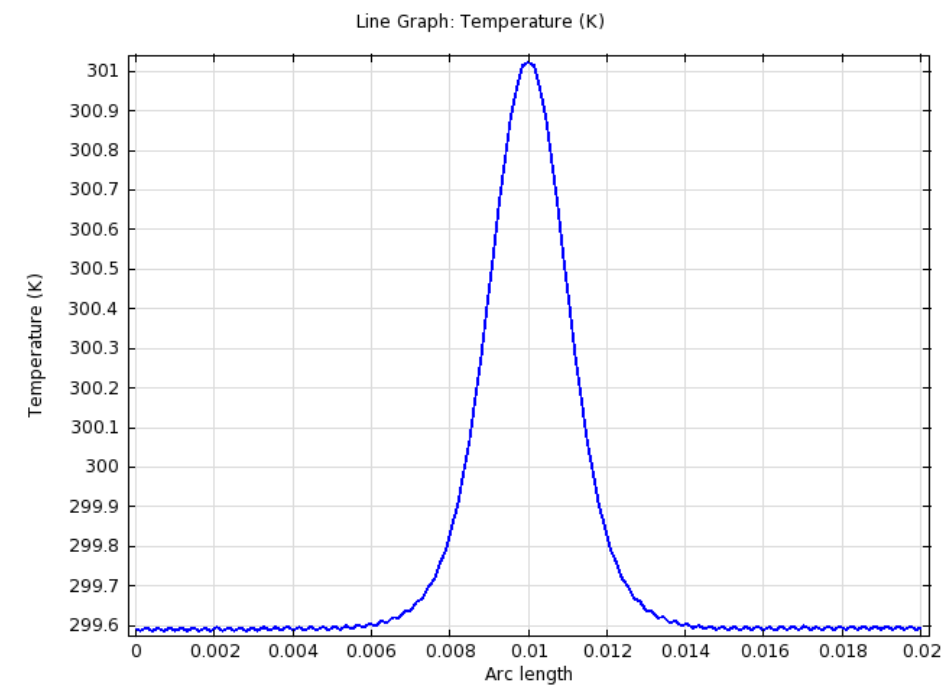

Fig. 10. Calculated surface temperature profile over the hidden defect (along the arrow in figure 9, right) showing the positive defect signal

Results from measurements and model calculations showing the defect signal (defect with depth position of $1.25 \mathrm{~mm}$ ) as a function of the frequency from $300 \mathrm{~Hz}$ to $2600 \mathrm{~Hz}$ are presented in figure 11 . In each case the signal is normalized to the value at $300 \mathrm{~Hz}$. The measurement signal is increasing with the frequency but the simulated data show a stronger increase. This discrepancy can be explained by the fact that the model calculation is two dimensional. This means that the plate as well as the defect are assumed to have an extension to infinity perpendicular to the image plane. Therefore the eddy currents on the back side of the plate always have to follow the crack flanks. In the case of the experimental geometry, due to the finite crack length of $10 \mathrm{~mm}$ the eddy currents propagating on the back side have the possibility to flow partially in lateral current paths along the crack. 


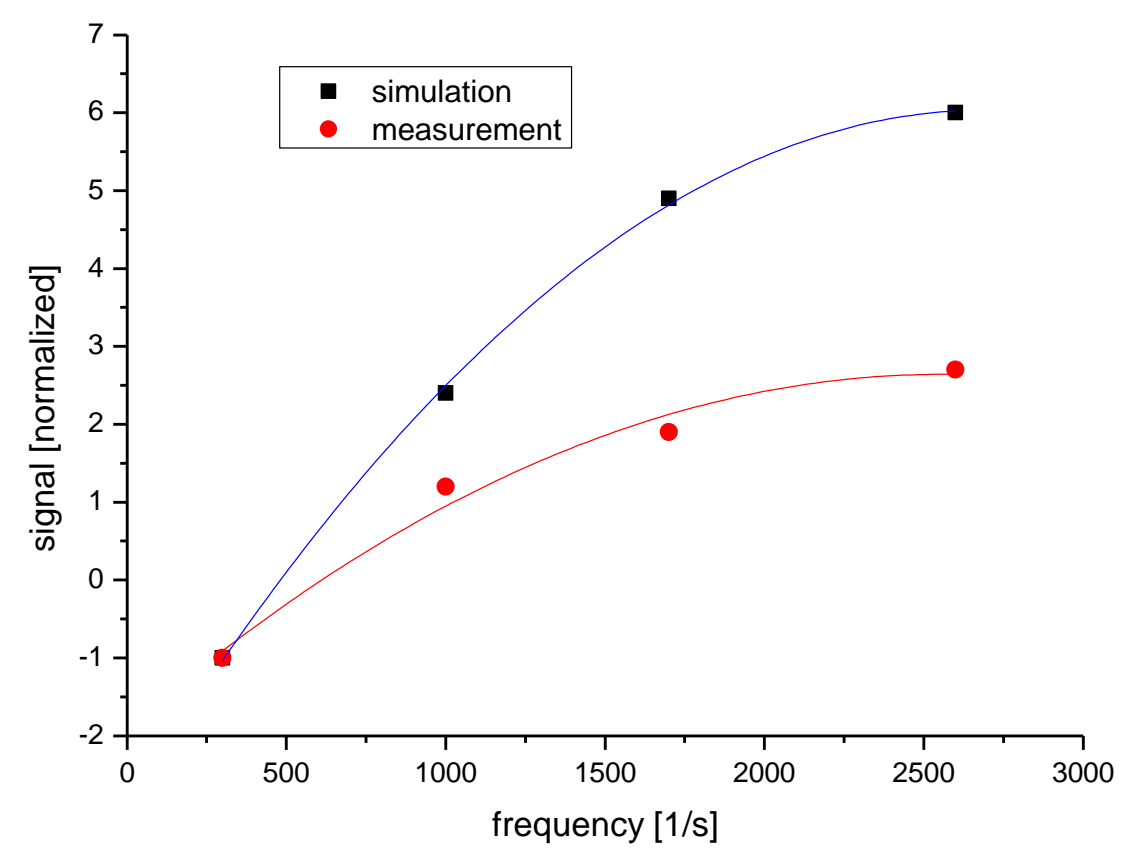

Fig. 11. Defect contrast as a function of the induction frequency for a hidden crack open to the specimen backside (1.25 $\mathrm{mm}$ depth position) from simulation and measurement. The signals are normalized to the absolute of the value at $300 \mathrm{~Hz}$.

\section{Conclusion}

Induction thermography can be performed in the frequency regime around $1 \mathrm{kHz}$, allowing to achieve sufficient electromagnetic skin depth to detect perpendicular oriented hidden crack-like defects in ferromagnetic steel with a coverage of $1 \mathrm{~mm}$ and more. Numerical simulation provides useful insight into the internal current flow lines and the resulting formation of thermal contrast inside and at the surface of specimens. The relation of optimum defect contrast and induction frequency was shown for different defect depth.

A special case occurs in plate-like geometries with long cracks starting from the back-side. Depending on the induction frequency, a positive or a negative defect contrast was observed and simulated. This may influence the probability of detection depending on the defect depth.

\section{REFERENCES}

[1] Bamberg J., Erbeck G., Zenzinger G., 'Eddy-Therm: Ein Verfahren zur bildgebenden Prüfung metallischer Bauteile', ZfP-Zeitung 68 (1999) 60-62

[2] Riegert G., Zweschper T., Busse G., 'Lockin thermography with eddy current excitation', QIRT Journal 1 (2004) 21-32

[3] Oswald-Tranta, B., 'Thermoinductive investigations of magnetic materials for surface cracks', QIRT Journal 1 (2004) 33-46

[4] Walle G., Netzelmann U., „Thermographic crack detection in ferritic steel components using inductive heating“. Proc. $9^{\text {th }}$ ECNDT Berlin, DGZfP Berichtsband BB 103-CD, paper Tu.4.8.5, 2006.

[5] Walle G., Valeske B., Netzelmann U., Bessert S., Strauß H., Wolf F., „Eine thermische Prüftechnik zur Oberflächenrissprüfung leitfähiger Materialien“. Materials Testing 9, pp. 593-602, 2009.

[6] Netzelmann U., Strauß H., Walle G., „Zerstörungsfreie thermographische Methoden zur Detektion von Fehlern in Massivumformteilen“. Schmiede-Journal, pp. 26-28, 2007.

[7] Valeske B., Walle G., Bessert S., „Aktive dynamische Thermographie und ihre Anwendung für die zerstörungsfreie Oberflächenrissprüfung“. QZ 53, pp. 66-69, 2008. 